\title{
DECISION MAKING FOR DEVICE CLOSURE IN ADULTS WITH ‘HYPERTENSIVE PDA'-NON-INVASIVE CRITERIA: IMMEDIATE RESULTS
}

\author{
Ahsan Beg, Abdul Malik*, Amjad Mahmood**, M Younas***, Fakher-e-Fayaz**** \\ Cardiac Center Quaid-e-Azam Medical College Bahawalpur Pakistan, *Rawalpindi Institute of Cardiology, Rawalpindi Pakistan, **Armed \\ Forces Institute of Cardiology/National Institute of Heart Disease (AFIC/NIHD)/National University of Medical Sciences (NUMS) \\ Rawalpindi Pakistan, ${ }^{* * * *}$ Combined Military Hospital Lahore/National University of Medical Sciences (NUMS) Pakistan
}

\begin{abstract}
Objective: To find the mean pulmonary artery pressures (PAP) in adults ( $>12$ years) Patent Ductus Arteriosus (PDA) with 'reversible pulmonary hypertension' after the device closure. Residual PDA and immediate complications (embolization, pulse loss, obstruction in the aorta or pulmonary artery) are to be reported.
\end{abstract}

Study Design: Retrospective study.

Place and Duration of Study: Tertiary Care Referral Hospital, from Aug 2007 to Jun 2020.

Methodology: This retrospective study is descriptive. Data collected by convenience sampling from 3 tertiary care referral hospital. 981 patients were undergone PDA device closure during the period from Aug 2007 to June 2020. After informed consent, an initial assessment was done by history, clinical examination, x-ray chest PA view, electrocardiography (ECG), and transthoracic echocardiography (TTE). Reversible pulmonary hypertension was labeled based on non-invasive criteria including room air saturation $>93 \%$ and cardiomegaly on x-ray chest. Patients who had $<93 \%$ and normal heart size on x-ray chest were excluded. The lower limit for age was 12 years. Results: Nine Hundred Eighty One patients had undergone PDA device closure. 32 (n=32/981 3.3\%) had fulfilled our inclusion criteria. The mean age was $22 \pm 9(13-45)$ years. Mean weight was $41 \pm 11(25-66) \mathrm{kg}$. Successful device closure was done in 30 patients $(93.7 \%)$. Mean diameter of PDA was $7 \pm 0.1$ (4.5-13 mm. Mean PAP decreased from $59 \pm 13 \mathrm{mmHg}$ to $38 \pm 19 \mathrm{mmHg}(p<0.05)$. Commonest device used was Shasma duct occluder $(n=16 / 3250 \%)$ followed by Occlutech Duct Occluder $(n=7 / 32$ 21.9\%), while 2 had muscular VSD device $(n=5 / 32$ 15.6\%). In 2 patients, there was an underestimation of the size of PDA so the device was retrieved and replaced with another larger one successfully. Two patients had the device fully dropped into the main pulmonary artery before it was released. Larger size device was not available at that time so the patients were referred for surgery. None of our patients had device embolization or residual shunt on echo performed next day to the procedure. Neither any patient had residual pulmonary hypertension on echocardiography. There was no significant obstruction in the aorta in any patients. Two patients had mild left pulmonary artery obstruction. There was no significant obstruction in the aorta in any of our patients. There was pulse loss in 3 patients which were treated successfully with heparin infusion with no residual damage.

Conclusion: Device closure is a feasible option in adults with hypertensive PDA while the decision of reversibility is based on non-invasive criteria.

Keywords: Adult congenital heart diseases, Congenital heart disease, Hypertensive PDA, PDA device closure, pulmonary hypertension.

This is an Open Access article distributed under the terms of the Creative Commons Attribution License (http://creativecommons.org/licenses/by/4.0), which permits unrestricted use, distribution, and reproduction in any medium, provided the original work is properly cited.

\section{INTRODUCTION}

Isolated patent ductus arteriosus (PDA) has an incidence of $10 \%$. Generally, it is closed by either by surgery or by the device. Untreated large size PDA can lead to heart failure or pulmonary hypertension. Developing countries have limited economic and health care facilities. Pov-

Correspondence: Dr Ahsan Beg, Cardiac Centre, QAMC Bahawalpur Pakistan erty, low literacy rate and late referral by the primary physician are contributing factors for delayed treatment. This contributes to morbidity and mortality for patients with congenital heart diseases. Untreated PDA lead to the development of pulmonary hypertension. This is progressive especially after the age of 2 years. However small no of these patients may not develop the pulmonary vascular obstructive disease even in 2 nd or 3rd decade of life. 
Due to large PDA, the pulmonary vascular bed is exposed to high pressure. This long-standing left to right shunt results in a progressive increase of pulmonary vascular resistance (PVR). When PVR exceeds systemic vascular resistance (SVR) shunting is reversed and becomes right to left, leading to Eisenmenger complex. It is important to decide, whether pulmonary hypertension is reversible or irreversible. Conventional methods include inhalation of $100 \%$ oxygen or balloon occlusion of PDA. Balloon occlusion and pulmonary vasodilator challenge have cost implications in resource-limited setup.

'Adults PDA' develop calcification and aneurysmal dilatationwith age. This leads to increased risk for surgical ligation in adults. Previous endarteritis, unusual anatomic features, and recurrent ductus are additional risk factors for surgery $^{1,2}$. Device closure of PDA is now well established ${ }^{3}$. One strategy is to proceed on 'fast track' with device closure based on non-invasive criteria. This interventional therapy in adults using device closure can play a key role to prevent progression toward irreversible pulmonary hypertension. Previously no data is reported in local literature for adults with hypertensive PDA using this 'fast track' strategy. The decision of reversibility is based on non-invasive methods.

\section{METHODOLOGY}

This retrospective study is descriptive. Data collected by convenience sampling from 3 tertiary care referral hospitals (Multan Institute of Cardiology, Rawalpindi Institute of Cardiology and Cardiac Center, Bahawalpur). Ethics committees of the respective hospitals granted permission. 981 patients were undergone PDA device closure during the period from Aug 2007 to June 2020. After informed consent, an initial assessment was done by history, clinical examination, x-ray chest PA view, electro-cardiography (ECG), and transthoracic echocardiography (TTE). Reversible pulmonary hypertension was labeled based on noninvasive criteria including room air saturation $>93 \%$ and cardiomegaly on x-ray chest. Patients who had $<93 \%$ and normal heart size on $x$-ray chest were excluded. The lower limit for age was 12 years. This non-invasive criterion was used instead of pulmonary vascular resistance (PVR) before and after $100 \%$ inhalation or balloon occlusion test. This had economic implications in a resource-limited setup like ours. So we proceeded with device closure using 'fast track' strategy for decision making about reversibility. Echocardiography was performed before and after the procedure. Size of PDA, pressure gradient and pulmonary artery pressures along with diastolic equalization pressures as per guidelines by the American Society of Echocardiography ${ }^{4}$, are documented. Color flow mapping was used to assess the direction of the shunt. Tricuspid regurgitation (TR) jet is used to assess systolic pulmonary artery pressures. Other factors (additional shunt lesion, left ventricular dysfunction, mitral valve abnormality, pulmonary venous stenosis) were ruled out. Mean pulmonary artery pressure $>50 \%$ of mean aortic pressures was defined as pulmonary hypertension. 32 patients with age $>12$ years with evidence of large PDA with reversible pulmonary hypertension were included in the study.

Devices were implanted using the anterograde approach after the femoral artery and femora venous access taken using local anesthesia and sedation. Heparin was used for anticoagulation (50-100 units/kg). Full lateral and 30 RAO angiograms delineated the size and shape of the ductus. PDA occlusion device was inserted through appropriately sized sheaths using standard techniques ${ }^{5}$. Mean pulmonary artery and mean aortic pressures were recorded in the catheterization laboratory. The device size was selected having $2-4 \mathrm{~mm}$ larger pulmonary end than the narrowest portion of PDA. The devices used were based upon availability, device size and its shape, and PDA shape along with the operator's choice.

Amplatzer ductoccluders (ADO I) (AGA Medical, MN, USA) and Amplatzer muscular ventricular septal defect occluders (AMVSDO) (AGA Medical, MN, USA).

Shasma duct occluder (Shanghai Shape Memory Alloy SHSMA, Shanghai, China). Occlu- 
tech duct occluder (ODO) (Occlutech International AB, Sweden). Cera PDA occluder (Lifetech Scientific, Shenzhen Co, Ltd.

Mean aortic (AO) and pulmonary artery pressures (PAP) were noted in room air and post 10 min of oxygen inhalation using venture mask $(60 \%)$. Balloon occlusion was done where ever appropriate size balloon was available using

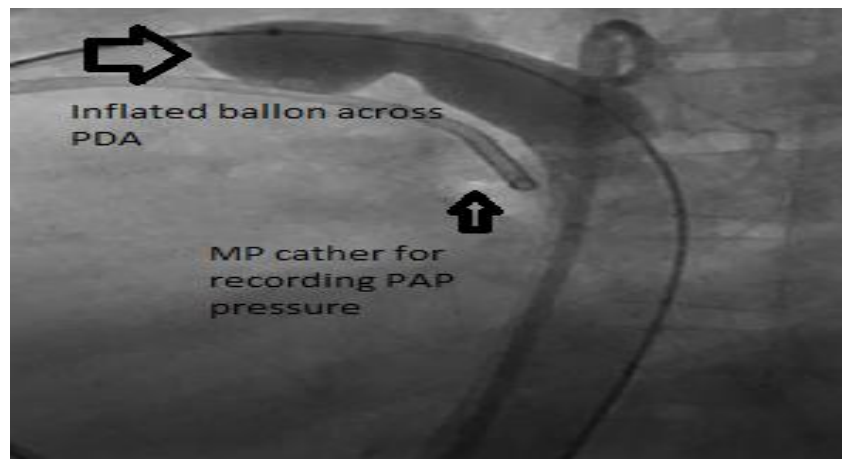

Figure-1: Balloon Occlusion Test.

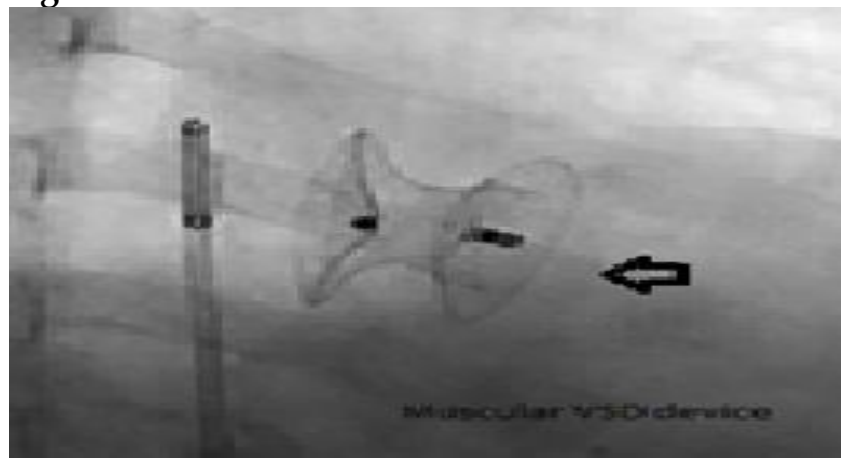

Figure-2: Muscular VSD device in the position.

Osypka balloon VACS II/III balloon (Osypka AG, Rheinfelden, Germany) via 2nd femoral venous access (fig-1). If mean PAP reduced by $>20 \%$, pulmonary hypertension was labeled to be reversible. After insertion of the device, aortogram was done to look for any residual PDA (fig2-4). All pulses were checked to evaluate any pulse loss. In the case of pulse loss, heparin infusion was started until the pulse became palpable. On $1^{\text {st }}$ post procedure day, echocardiography was done to evaluate any residual PDA, estimate the mean PAP and protrusion of PDA device into aorta or the pulmonary artery. Patients who had residual pulmonary hypertension were discharged on oral pulmonary vasodilator (oral sildenafil). Complications were noted for every patient.
Three days of antibiotic therapy was given to every patient for infection prevention.

Performa filled for every patient. Variable (age, weight, Mean Ao pressures, mean PAP before and after device closure/oxygen test/ balloon occlusion test) were analyzed using SPSS

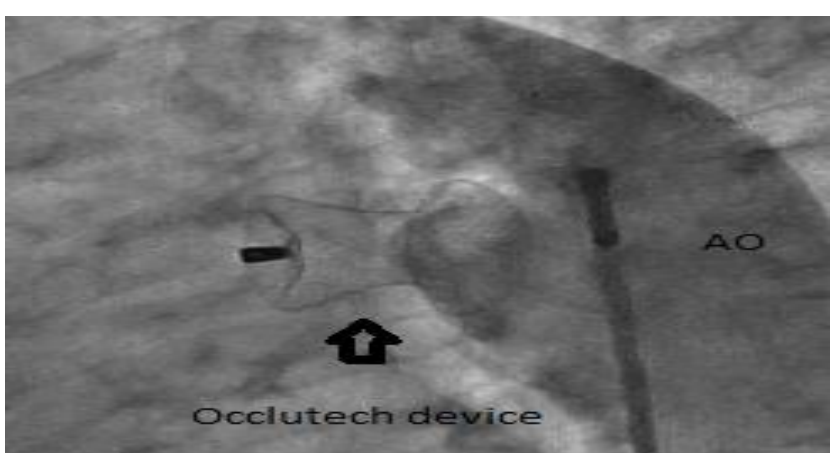

Figure-3: Occlutech Device in Position.

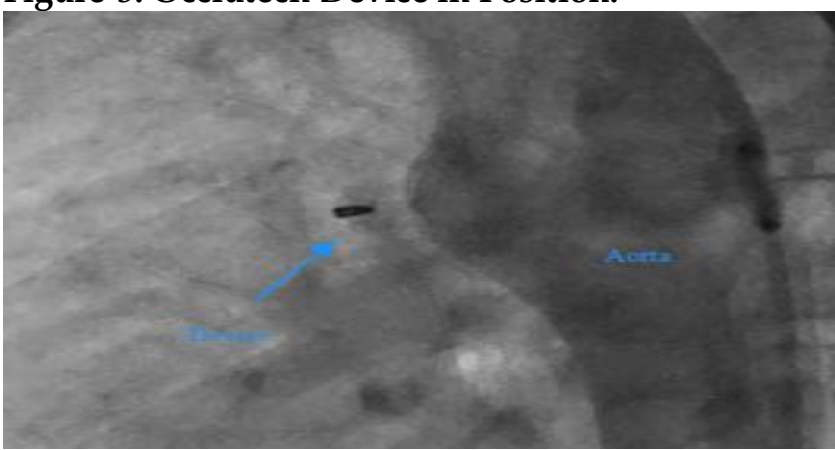

Figure-4: ADO I in the Positon.

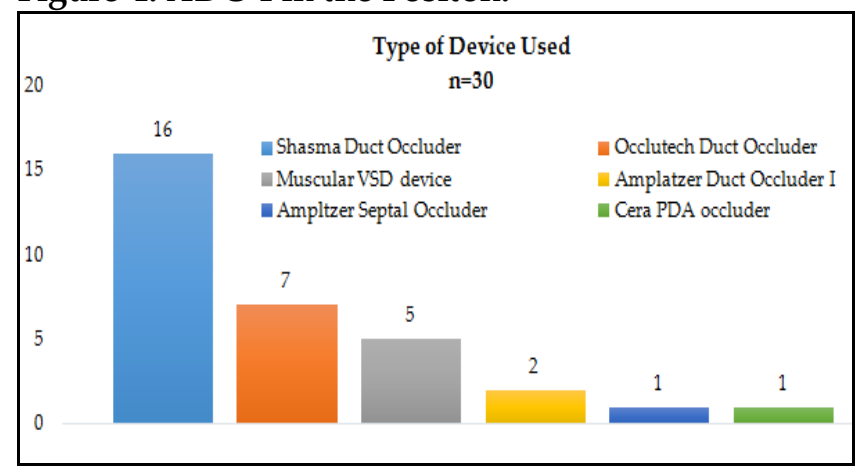

Figure-5: Devices used and numbers.

(version 24). Test of significance ( $p$-value $<0.001$ ) was used for mean PAP before and after the procedure. Success was based on significant reduction of mean PAP after the device closure and no residual shunt.

\section{RESULTS}

This is a retrospective descriptive multicenter study from a period from 2007 to June 2020. 
All three centers are tertiary care dedicated cardiac hospitals. Adult patients (>12 years) who had large PDA with pulmonary hypertension $(\mathrm{PH})$ were included. Mean PAP $>50 \%$ of mean aortic pressure $(\mathrm{AO})$ was considered as pulmonary hypertension. The reversibility of $\mathrm{PH}$ was were excluded. Patients with irreversible pulmonary hypertension were excluded. Patients whom other associated cardiac lesions which were the indicator for surgery were also excluded.

Nine hundred and eighty one patients had

Table-I: Data $(n=32)$ there was no significant obstruction in aorta in any of our patient. there was pulse loss in 3 patients which was treated successfully with heparin infusion with no residual damage.

\begin{tabular}{|c|c|c|c|}
\hline \multicolumn{4}{|l|}{ Parameters } \\
\hline \multicolumn{2}{|l|}{ Mean Age with Standard Deviation SD (Years) } & \multicolumn{2}{|c|}{$22 \pm 9(13-45)$ years } \\
\hline \multicolumn{2}{|l|}{ Mean Weight with SD (Kg) } & \multicolumn{2}{|c|}{$41 \pm 11(25-66) \mathrm{kg}$} \\
\hline \multicolumn{2}{|l|}{ PDA Device Closure Performed } & \multicolumn{2}{|c|}{$\mathrm{n}=981$} \\
\hline \multicolumn{2}{|c|}{ Adult Hypertensive PDA with Attempted Device Closure } & \multicolumn{2}{|c|}{$32(32 / 9813.3 \%)$} \\
\hline \multicolumn{2}{|l|}{ Successful Device Closure } & \multicolumn{2}{|c|}{$30 / 32(93.7 \%)$} \\
\hline \multicolumn{2}{|l|}{ Hypertensive PDA Failed / Abandoned Attempt } & \multicolumn{2}{|c|}{$2 / 32(6.3 \%)$} \\
\hline \multicolumn{2}{|c|}{ Mean Flouro with SD Time (Record Available From One Center Only) } & \multicolumn{2}{|c|}{$9.5 \pm 3.2$ minutes } \\
\hline \multicolumn{2}{|l|}{ Mean Procedure Time with SD (for one center) } & \multicolumn{2}{|c|}{$51 \pm 32$ minutes } \\
\hline \multicolumn{4}{|l|}{ Table-II: Shows the hemodynamics (mean with SD). } \\
\hline Mean PA pressure with SD (pre-device) & \multicolumn{3}{|c|}{$59 \pm 13 \mathrm{mmHg}$} \\
\hline Mean Ao pressure with SD (pre-device) & \multicolumn{3}{|c|}{$99 \pm 16 \mathrm{mmHg}$} \\
\hline Mean PA pressure with SD (post-device) & \multicolumn{3}{|c|}{$38 \pm 19 \mathrm{mmHg}$} \\
\hline Mean Ao pressure with SD (post-device) & \multicolumn{3}{|c|}{$89 \pm 14 \mathrm{mmHg}$} \\
\hline PVR before/after device occlusion & \multicolumn{3}{|c|}{ Assessed in only one patient } \\
\hline Trial by balloon occlusion & \multicolumn{3}{|c|}{$\mathrm{n}=4 / 32(12.5 \%)$} \\
\hline \multicolumn{4}{|c|}{ Table-III: Devices used successful cases (n and percentage with largest size used). } \\
\hline & & & n (\%) \\
\hline \multicolumn{3}{|c|}{$\begin{array}{l}\text { Shasma Duct Occluder (Shanghai Shape Memory Alloy SHSMA, Shanghai, China) - } \\
\text { largest size use 18/16 }\end{array}$} & $16 / 30(53.3 \%)$ \\
\hline \multicolumn{3}{|c|}{$\begin{array}{l}\text { Occlutech Duct Occluder (Occlutech International AB, Sweden) } \\
\text { Largest size used was } 18 / 14 \mathrm{~mm}\end{array}$} & $7 / 30(23.3 \%)$ \\
\hline \multicolumn{3}{|c|}{ Muscular VSD device (AGA Medical, MN, USA). Largest size used was $18 \mathrm{~mm}$} & $5 / 30(16.7 \%)$ \\
\hline \multicolumn{3}{|c|}{ Amplatzer Duct Occluder I (AGA Medical, MN, USA). Largest size used was 14/12 mm } & $2 / 30(6.7 \%)$ \\
\hline \multicolumn{3}{|c|}{ Ampltzer Septal Occluder (AGA Medical, MN, USA). $20 \mathrm{~mm}$} & $1 / 30(3.3 \%)$ \\
\hline \multicolumn{3}{|c|}{ Cera PDA occluder (LifetechScientific, Shenzhen Co., Ltd. China. 12/10 mm used. } & $1 / 32(3.3 \%)$ \\
\hline Table-IV: Complications (n with Percentage). & & & \\
\hline Residual PDA & & & \\
\hline Pulse loss & & & \\
\hline Referral for Surgery After Abandoned Procedure & & & \\
\hline Embolized device & & & \\
\hline LPA obstruction (mild) & & & \\
\hline Aortic obstruction & & & \\
\hline Pre-device treatment with vasodilator-not known & & & \\
\hline Post-device treatment with vasodilator & & & \\
\hline
\end{tabular}

based on non-invasive criteria. Patients with room air saturation $>93 \%$, cardiomegaly on chest $\mathrm{x}$-ray were considered to have reversible pulmonary hypertension. Patients with age $<12$ years undergone PDA device closure. Thirty two $(n=32$ /981 3.3\%) had fulfilled our inclusion criteria. The mean age was $22 \pm 9(13-45)$ years. Mean weight was $41 \pm 11$ (25-66) kg (table-I). Successful 
device closure was done in 30 patients (93.7\%). The mean diameter of PDA was $7 \pm 0.1$ (4.5-13 $\mathrm{mm})$. Mean PAP decreased from $59 \pm 13 \mathrm{mmHg}$ to $38 \pm 19 \mathrm{mmHg}(p<0.05)$ (table-II). Commonest device used was Shasma duct occluder $(n=16 / 32$, $50 \%)$ followed by Occlutech Duct Occluder ( $n=7 /$ 32 21.9\%), while 2 had muscular VSD device $(n=5 / 32,15.6 \%)$ (table-III, Graph 1). In 2 patients, there was an under-estimation of the size of PDA so the device was retrieved and replaced with another larger one successfully. Two patients had the device fully dropped into the main pulmonary artery before it was released. Larger size device was not available at that time so the patients were referred for surgery. None of our patients had device embolization or residual shunt on echo performed next day to the procedure. Neither any patient had residual pulmonary hypertension on echocardiography. There was no significant obstruction in aorta in any patients. 2 patients had mild left pulmonary aorta obstruction (table-IV).

\section{DISCUSSION}

The diagnosis of congenital heart diseases is often delayed in developing countries. PDA is about $15 \%$ of all adult congenital heart diseases ${ }^{6}$. Multiple factors contribute to this phenomenon including poverty, ignorance, late diagnosis by the attending physician or cardiologist and few available cardiac centers. Training of adult cardiologists for congenital heart diseases is also questionable. Surgery is one option of treatment. But calcification and aneurysmal dilatation are surgical risk factors. Varieties of devices are now available in Pakistan but we had limited options at our hospitals. So data from others also collected.

We included adults ( $>12$ years) with large PDA and pulmonary hypertension (defined as mean PAP $>50 \%$ of mean aortic pressures). The prognosis depends on whether pulmonary hypertension is reversible or not. Balloon occlusion of PDA temporarily blocks the duct and hemodynamic can be reassessed afterward which are considered to more reliable than oxygen inhalation tests. But the position of the balloon is to be maintained for 10 minutes during balloon occlusion test. If the balloon position is unstable, false results might be reported. 100\% oxygen inhalation requires the services of anesthetists in the catheterization laboratory. However, theuse of venture masks gives only $60 \%$ oxygen. So we proceeded on 'fast track' to cut down the cost and save time. This is less cumbersome than a balloon occlusion test. So protocols need to be tailored in developing countries as we did in our study. But one 'risk' was the non-reversible pulmonary hypertension even after device occlusion of the PDA. So careful assessment is necessary before the release of the device. The cost of the retrieved device would be another issue. However, we did not face this situation in any of our cases. So the selection of patients for this 'fast track' would be key to success.

Sadiq et al, reportedsevere pulmonary hypertension was persistent in four $(9.7 \%)$ patients (for all age groups) at follow-up of 80 (41-151) months ${ }^{7}$. The same phenomena were documented in $4 / 43$ patients at a median follow up of 80 months (range $41-151$ months) ${ }^{8}$. But none of our patients had persistent high pressures on echo performed the next day to the procedure. Whether follow up is still needed in our cases? This question remains answerable. However, only $40 \%(n=12 / 30)$ of our patients had mean PA pressures $>2 / 3$ of mean systemic pressures. This might be another factor in the regression of mean PAP after the device closures.

Beneficial effects of pre-medication with pulmonary vasodilators like sildenafil are reported. This factor is not documented in our study ${ }^{9}$. Risk of device embolization increased in cases with severe pulmonary hypertension. Shapes of muscular VSD device (double disks) and Occlutech device (wider pulmonary artery end) reduces this risk. These were used $40 \%(n=12 / 30)$ of our cases. For other devices (like ADO I) in the study, we oversized by $2-4 \mathrm{~mm}$ than the narrow point of PDA. A similar strategy is reported by other authors as well in patients with large PDA (>4 $\mathrm{mm})^{10}$. 
$\mathrm{Yu}$ et al11, reported success in 19 adult patients who had large PDA (>10 mm) with reversible who pulmonary hypertension using Shasma Duct Occluder (used in 53\% of our cases $n=16 / 30$ ). Follow up of these patients showed no residual shunt. However, the no of patients in this study had residual shunt immediately after the procedure. One recent local study reported device closure in adults ( $>18$ years; $n=25)$. However, they did not report mean PAP before and after the device closure ${ }^{12}$. Zabal et al ${ }^{13}$, reported that device closure is safe and effective in 158 selected patients (with mean PAP >50 mmHg). Alkashkari et al reported successful implantation in 27 adult patients over a period of 10 years ${ }^{14}$. Wilson et al described results of 141 adult patients and $36 \%$ of the patients had pulmonary hypertension $^{15}$. Sudhakar had documented immediate and sustained drop in pulmonary artery in adult patients with baseline reversible severe $\mathrm{PAH}^{16-18}$.

\section{CONCLUSION}

Device closure is a feasible option in adults with hypertensive PDA while the decision of reversibility is based on non-invasive criteria.

\section{CONFLICT OF INTEREST}

This study has no conflict of interest to be declared by any author.

\section{REFERENCES}

1. Toda R, Moriyama $Y$, Yamashita M, Iguro $Y$, Matsumoto $H$, Yotsumoto G. Operation for adult patent ductus arteriosus using cardiopulmonary bypass. Ann Thorac Surg 2000; 70(1): 1935-38.

2. Taira A, Akita H. Patch closure of the ductus arteriosus: an improved method. Ann Thorac Surg 1976; 21(5): 454-55.

3. Ewert P. Challenges encountered during closure of patent ductus arteriosus. Pediatr Cardiol 2005; 26(3): 224-22.

4. Rudski LG, Lai WW, Afilalo J, Hua L, Mark D, Chandrasekaran $\mathrm{K}$, et al. Guidelines for the echocardiographic assessment of the right heart in adults: a report from the American society of echocardiography endorsed by the European association of echocardiography, a registered branch of the European society of cardiology, and the Canadian society of echocardiography. J Am Soc Echocardiogy 2010; 23(7): 685-13.

5. Masura J, Walsh KP, Thanopoulos B. Catheter closure of moderate-to-large sized patent ductus arteriosus using the new amplatzer duct occluder: immediate and short-term results. J Am Coll Cardiol 1998; 31(4): 878-82.

6. Shabbir M, Akhtar K, Maadullah. Transcatheter closure of large sized patent ductus arteriosus using the amplatzer duct occluder device. J Coll Phy Surg Pak 2009; 19(5): 275-78.

7. Sadiq M, Rehman AU, Hyder N, Qureshi AU, Kazmi T, Qureshi SA. Intermediate- and long-term follow-up of device closure of patent arterial duct with severe pulmonary hypertension: factors predicting outcome. Cardiol Young 2016; 27(1): 26-36.

8. Viswanathan S, Kumar K. Assessment of operability of congenital cardiac shunts with increased pulmonary vascular resistance. Catheter Cardiovasc 2008; 71(5): 665-70.

9. Yan C, Zhao S, Jiang S, Xu Z,. Transcatheter closure of patent ductus arteriosus with severe pulmonary arterial hypertension in adults. Heart 2007; 93(4): 514-18.

10. Sheikh AM, Shebani SO, Duk C. The occlutech duct occluder: How to choose the correct device size and refine implantation technique to ensure optimal results in small and large arterial duct closure. Interv Cardiol 2019; 11(6): 113-11.

11. Yu M, Huang $X$, Wang J. Safety and efficacy of transcatheter closure of large patent ductus arteriosus in adults with a selfexpandable occluder. Heart Vessels 2009; 24(6): 440-45.

12. Khan ZA, Sultan M, Ullah M, kamran J, Siddiqa A, Siddiqa AH, et al. Patent ductus arteriosus device closure in grown up patients. Pak Armed Forces Med J 2019; 69(Suppl-1): S134-37.

13. Zabal C, Garcia-Montes JA, Buendia-Hernandez A, CalderónColmenero J, Patiño-Bahena E, et al. Percutaneous closure of hypertensive ductus arteriosus Heart 2010; 96(8): 625-29.

14. Alkashkari W, Albugami S, Alrahimi J. Percutaneous device closure of patent ductus arteriosus in adult patients with 10-year follow-up. Heart Views 2019; 20(4): 139-45.

15. Wilson WM, Shah A, Osten MD, Benson LN,. Clinical Outcomes After Percutaneous Patent Ductus Arteriosus Closure in Adults. Can J Cardiol 2020; 36(6): 837-43.

16. PS, Jose J, George OK. Contemporary outcomes of percutaneous closure of patent ductus arteriosus in adolescents and adults. Indian Heart J 2018; 70(2): 308-315.

17. Putra ST, Djer MM, Idris NS, Sastroasmoro S. Transcatheter closure of patent ductus arteriosus in adolescents and adults: a case series. Acta Med Indones 2016;48(4):314-319.

18. Behjati-Ardakani M, Rafiei M, Behjati-Ardakani MA, Vafaeenasab M, Sarebanhassanabadi M. Long-term results of transcatheter closure of patent ductus arteriosus in adolescents and adults with amplatzer duct occluder. N Am J Med Sci 2015; 7(5): 208-211. 